Journal Club

Editor's Note: These short, critical reviews of recent papers in the Journal, written exclusively by graduate students or postdoctoral fellows, are intended to summarize the important findings of the paper and provide additional insight and commentary. For more information on the format and purpose of the Journal Club, please see http://www.jneurosci.org/misc/ifa_features.shtml.

\title{
Losing Connections, Losing Memory: AMPA Receptor Endocytosis as a Neurobiological Mechanism of Forgetting
}

\author{
Axel J Guskjolen \\ Program in Neuroscience and Mental Health, The Hospital for Sick Children, Toronto, Ontario M5G 1X8, Canada, and Department of Physiology, \\ University of Toronto, Toronto, Ontario M5S 1A8, Canada \\ Review of Migues et al.
}

Although much is known about how memories are formed (Josselyn et al., 2015), much less research has focused on the neurobiological mechanisms underlying forgetting. This is likely due to the implicit, yet incorrect, belief that forgetting is a failure in neural processing whereby memories are simply broken down as a function of time. In fact, forgetting is a mechanistically controlled and adaptive phenomenon that facilitates future mnemonic processing (Epp et al. 2016). With this recognition, recent years have witnessed a surge in investigations of the neurobiology of forgetting.

Successful memory retrieval is thought to occur by reactivating the spatiotemporal pattern of neuronal activity that was present at encoding (i.e., pattern completion). When the circuitry that underlies a memory is disrupted, the probability of successful pattern completion is decreased, ultimately culminating in forgetting. In other words, at a basic level, making memories involves making connections, and breaking memories involves breaking connections. In line with this idea, recent work by Migues et al. (2016) sought to determine whether the stability of GluA2-containing AMPA receptors

Received May 2, 2016; revised June 5, 2016; accepted June 9, 2016. I thank Paul Frankland for his encouragement and input.

Correspondence should be addressed to Axel I Guskjolen, Peter Gilgan

Centre for Research and Learning, 686 Bay Street, 5th Floor, Toronto, ON M5G 0A4, Canada. E-mail: aguskjolen@gmail.com.

DOI:10.1523/JNEUROSCI.1445-16.2016

Copyright $\odot 2016$ the authors $\quad 0270-6474 / 16 / 367559-03 \$ 15.00 / 0$
(GluA2/AMPARs), which play an important role in the persistence of memory across time, also regulate the forgetting of consolidated memories, as was predicted by Hardt et al. (2014). Consistent with a general framework in which forgetting is caused by a disruption in the synaptic connectivity upon which memories are dependent, Migues et al. (2016) provide compelling evidence that forgetting ensues as dorsal hippocampal GluA2/ AMPAR synapses are lost.

The researchers first used an objectlocation task in which rats were exposed to two identical objects located in fixed places over a period of many days. After training, one of the objects was moved to a new location. This task takes advantage of rodents' innate tendency to explore novelty. Thus, if the rat remembers the objects' previous location, it will preferentially explore the moved object. Using this task, it was found that rats display memory for a moved object for at least $7 \mathrm{~d}$, but lack this preference by 10-14 d (Migues et al., 2016, their Fig. 1B).

Having established a behavioral protocol that reliably produces forgetting, the authors next asked whether GluA2/ AMPAR endocytosis mediates forgetting of object-location memories. To answer this question, the synthetic interference peptide GluA2 $2_{3 Y}$, which obstructs activity-dependent removal of synaptic AMPARs, was used. Following training in the object location task, GluA2 3 (or its inactive control) was infused twice daily into the dorsal hippocampus for the next
$13 \mathrm{~d}$, by which point natural forgetting has occurred. Memory retention was tested $24 \mathrm{~h}$ following the last infusion. Fascinatingly, whereas control rats once again lacked a preference for the moved object, inhibiting GluA2/AMPAR endocytosis with GluA2 3 Y completely reversed this forgetting phenotype (Migues et al., 2016, their Fig. 1E).

The results above suggest that activitydependent GluA2/AMPAR endocytosis mediates the forgetting of object-location memory. However, because treatment was begun immediately after training and forgetting did not occur for at least $7 \mathrm{~d}$ after training (Migues et al., 2016, their Fig. 1B), it is possible that GluA2 $2_{3 Y}$ strengthened consolidation of the memory trace rather than preventing forgetting, per se. Controlling for this possibility, GluA2 3 y was only given shortly before the animals began to forget, starting on day 8 . As before, memory performance was assessed on day 14 . GluA2 $2_{3 Y}$ was once again found to reverse natural forgetting, thereby substantiating the role of GluA2/AMPAR endocytosis in forgetting (Migues et al., 2016, their Fig. $2 E)$. However, the possibility that GluA2 $3 \mathrm{Y}$ prevents forgetting by enhancing memory retrieval specifically was not examined. This is possible given that forgetting is often found to be a reversible "failure" in memory retrieval (Li et al. 2014; Roy et al. 2016) and in light of the finding that perirhinal GluA2/ AMPA receptor endocytosis is required for the retrieval (but not the encoding or consolidation) of object recognition memory 
(Cazakoff and Howland, 2011). By infusing GluA2 $_{3 Y}$ closer to memory assessment, the potential role of GluA2/AMPAR endocytosis in retrieval of a forgotten memory could have been determined.

Migues et al. (2016) next assessed whether GluA2/AMPAR endocytosis mediates forgetting of associative memories, using a conditioned place preference (CPP) task in which one of two contexts was paired with reward. In this task, animals typically spend more time exploring the food-associated context. Migues et al. (2016) confirmed that the CPP task resulted in a memory that was forgotten over $10 \mathrm{~d}$ (Migues et al., 2016, their Fig. $4 B)$. Next, GluA2 3 or its inactive control was infused into the dorsal hippocampus (twice daily) throughout the interval between training and test. As predicted, suppressing synaptic removal of GluA2/ AMPARs increased the amount of time the rats spent in the food-paired context when tested on day 10 (Migues et al., 2016, their Fig. 4E). This suggests that activity-dependent GluA2/AMPAR endocytosis mediates the forgetting of appetitive associative memories.

Next, the authors assessed whether GluA2/AMPAR endocytosis regulates time-dependent memory changes that relate to, but are distinct from, forgetting by examining the generalization of a contextual fear memory. In this paradigm, rats are trained to express fear in a specific context. Over the subsequent $\geq 2$ weeks, rats typically generalize their fear response to contexts in which they were never trained. Although many factors underlie fear generalization, forgetting the details of the original context in which training occurred plays an important role (Riccio and Joynes, 2007; Wiltgen and Silva, 2007; Jasnow et al. 2012). Migues et al. (2016) confirmed that fear generalization occurred over a period of 2 weeks (Migues et al., 2016, their Fig. 5B) and then infused GluA2 3 into the dorsal hippocampus of rats throughout the $13 \mathrm{~d}$ between training and test. Consistent with a role of synaptic GluA2/AMPARs in memory generalization, GluA2 $3 Y$ preserved the specificity (possibly via reducing the forgetting of details) of the context memory across the 2 week period (Migues et al., 2016, their Fig. 5D).

How does GluA2/AMPAR endocytosis mediate forgetting? Previous research has demonstrated that GluA2 3 inhibits the induction of LTD without affecting basal synaptic transmission or induction of LTP (Yu et al., 2008). However, whether GluA2/AMPAR endocytosis plays a role in synaptic depotentiation (i.e., decay) of LTP is unknown. To address this question, GluA2/AMPAR endocytosis was inhibited during stimulation of the Schaffer collateral (CA3-CA1) pathway in hippocampal slices. Migues et al. (2016) first established that delivering low-frequency stimulation depotentiates LTP (Migues et al., 2016, their Fig. 7A). Next, they demonstrated that intracellular delivery of GluA2 $2_{3 Y}$, but not its inactive control, blocked this depotentiation (Migues et al., 2016, their Fig. 7B). Together, these results suggest that activity-dependent GluA2/AMPAR endocytosis likely mediates forgetting through regulating both the induction of LTD and the depotentiation of LTP (Dong et al. 2015; Migues et al., 2016, their Fig. $7 B, C)$. This explanation is congruent with recent work demonstrating a role for LTD and LTP in failed and successful memory retrieval, respectively (Nabavi et al., 2014). Together, these data suggest that inhibiting the removal of GluA2/AMPARs "locks" that current state of connectivity, preserving synaptic potentiation, thereby preventing the loss of the information stored in those circuits (i.e., forgetting).

Research into the neurobiological mechanisms of forgetting has begun to blossom, with important results being found across a variety of species, including Caenorhabditis elegans (Inoue et al., 2013; Hadziselimovic et al. 2014); Drosophila (Shuai et al., 2010; Berry et al. 2012; Cervantes-Sandoval et al., 2016); mice, degus, and guinea pigs (Akers et al., 2014; Epp et al., 2016); and rats (Dong et al., 2015; Migues et al., 2016; Sachser et al., 2016). Synthesizing this seemingly diverse collection of results into a unified framework is an important task. The work of Migues et al. (2016) is consistent with a preliminary model, whereby "unlocking" and disrupting the circuit in which a memory is embedded culminates in forgetting. This "destructive circuit remodeling" can occur via the elimination of synaptic connections that are essential to the memory trace or the addition of mnemonically irrelevant synaptic connections into a memory circuit; in either case, the rewiring would render pattern completion more difficult, culminating in forgetting. In the current work, postlearning loss of GluA2/AMPAR connectivity resulted in forgetting. Consistent with this, AMPA-type glutamate receptor-containing synapse size regulates forgetting in C. elegans, with synaptic shrinkage (i.e., loss of connectivity) leading to forgetting (Hadziselimovic et al. 2014). These alterations in synaptic architecture were mediated by the Arp2/3 complex, which controls actin cytoskeletal nucleation and branching (Hadziselimovic et al. 2014), a result that is consistent with the involvement of actin cytoskeleton regulation in AMPAR trafficking more generally (Hanley, 2014). Similarly, the Rho GTPase Racl bidirectionally modulates forgetting in Drosophila, likely through the regulation of actin cytoskeleton dynamics (Shuai et al., 2010; CervantesSandoval et al., 2016). Following the basic model of forgetting outlined here, one would predict that Rac1-mediated forgetting would result from the shrinkage or elimination of spines relevant to the memory trace, but this has yet to be tested directly. In rodents, we recently found that postlearning neurogenesis causes forgetting of hippocampal-dependent information learned $\geq 28 \mathrm{~d}$ earlier (Akers et al., 2014). We have hypothesized that neurogenesis causes forgetting by rewiring the circuitry in which the memory is embedded through the addition of new synaptic connections as well as the elimination of pre-existing connections (Frankland et al., 2013), a result that likely depends on Rac1-mediated cytoskeletal remodeling (Vadodaria et al. 2013). It is also possible that that the infiltration of new neurons into hippocampal circuitry results in a net increase in circuit excitability. This increased excitability might trigger homeostatic mechanisms that reduce the excitability of surrounding neurons through GluA2/AMPAR endocytosis (Frankland et al., 2013), with the loss of these receptors inducing forgetting, a finding that would complement the results obtained by Migues et al. (2016). Together, these findings converge on the idea that just as making memories involves making connections, breaking memories involves breaking connections.

\section{References}

Akers KG, Martinez-Canabal A, Restivo L, Yiu AP, De Cristofaro A, Hsiang HLL, Wheeler AL, Guskjolen A, Niibori Y, Shoji H, Ohira K, Richards BA, Miyakawa T, Josselyn SA, Frankland PW (2014) Hippocampal neurogenesis regulates forgetting during adulthood and infancy. Science 344:598-602. CrossRef

Berry JA, Cervantes-Sandoval I, Nicholas EP, Davis RL (2012) Dopamine is required for learning and forgetting in Drosophila. Neuron 74:530-542. CrossRef Medline

Cazakoff BN, Howland JG (2011) AMPA receptor endocytosis in rat perirhinal cortex underlies retrieval of object memory. Learn Mem 18:688-692. CrossRef Medline

Cervantes-Sandoval I, Chakraborty M, MacMullen C, Davis RL (2016) Scribble scaffolds a signalosome for active forgetting. Neuron. Advance online publication. Retrieved May 31, 2016. doi:10.1016/j.neuron.2016.05.010. CrossRef Medline

Dong Z, Han H, Li H, Bai Y, Wang W, Tu M, Peng 
Y, Zhou L, He W, Wu X, Tan T, Liu M, Wu X, Zhou W, Jin W, Zhang S, Sacktor TC, Li T, Song W, Wang YT (2015) Long-term potentiation decay and memory loss are mediated by AMPAR endocytosis. J Clin Invest 125: 234-247. CrossRef Medline

Epp JR, Silva Mera R, Köhler S, Josselyn SA, Frankland PW (2016) Neurogenesis-mediated forgetting minimizes proactive interference. Nat Commun 7:10838. CrossRef Medline

Frankland PW, Köhler S, Josselyn SA (2013) Hippocampal neurogenesis and forgetting. Trends Neurosci 36:497-503. CrossRef Medline

Hadziselimovic N, Vukojevic V, Peter F, Milnik A, Fastenrath M, Fenyves BG, Hieber P, Demougin P, Vogler C, de Quervain DJ, Dominique JF, Papassotiropoulos A, Stetak A (2014) Forgetting is regulated via Musashi-mediated translational control of the Arp2/3 complex. Cell 156:1153-1166. CrossRef Medline

Hanley JG (2014) Actin-dependent mechanisms in AMPA receptor trafficking. Front Cell Neurosci 8:381. CrossRef Medline

Hardt O, Nader K, Wang YT (2014) GluA2dependent AMPA receptor endocytosis and the decay of early and late long-term potentiation: possible mechanisms for forgetting of short-and long-term memories. Philos Trans
R Soc Lond B Biol Sci 369:20130141. CrossRef Medline

Inoue $\mathrm{A}$, Sawatari E, Hisamoto N, Kitazono $\mathrm{T}$, Teramoto T, Fujiwara M, Matsumoto K, Ishihara T (2013) Forgetting in C. elegans is accelerated by neuronal communication via the TIR-1/JNK-1 pathway. Cell Rep 3:808-819. CrossRef Medline

Jasnow AM, Cullen PK, Riccio DC (2012) Remembering another aspect of forgetting. Front Psychol 3:175. CrossRef Medline

Josselyn SA, Köhler S, Frankland PW (2015) Finding the engram. Nat Rev Neurosci 16: 521-534. CrossRef Medline

Li S, Callaghan BL, Richardson R (2014) Infantile amnesia: forgotten but not gone. Learn Mem 21:135-139. CrossRef Medline

Migues PV, Liu L, Archbold GE, Einarsson EÖ, Wong J, Bonasia K, Ko SH, Wang YT, Hardt O (2016) Blocking synaptic removal of GluA2containing AMPA receptors prevents the natural forgetting of long-term memories. J Neurosci 36:3481-3494. CrossRef Medline

Nabavi S, Fox R, Proulx CD, Lin JY, Tsien RY, Malinow R (2014) Engineering a memory with LTD and LTP. Nature 511:348-352. CrossRef Medline

Riccio DC, Joynes RL (2007) Forgetting of stimulus attributes: some implications for hippocampal models of memory. Learn Mem 14: 430-432. CrossRef Medline
Roy DS, Arons A, Mitchell TI, Pignatelli M, Ryan TJ, Tonegawa S (2016) Memory retrieval by activating engram cells in mouse models of early Alzheimer's disease. Nature 531: 508-512. CrossRef Medline

Sachser RM, Santana F, Crestani AP, Lunardi P, Pedraza LK, Quillfeldt JA, Hardt O, de Oliveira Alvares L (2016) Forgetting of longterm memory requires activation of NMDA receptors, L-type voltage-dependent $\mathrm{Ca}(2+)$ channels, and calcineurin. Sci Rep 6:22771. CrossRef Medline

Shuai Y, Lu B, Hu Y, Wang L, Sun K, Zhong Y (2010) Forgetting is regulated through Rac activity in Drosophila. Cell 140:579-589. CrossRef Medline

Vadodaria KC, Brakebusch C, Suter U, Jessberger S (2013) Stage-specific functions of the small Rho GTPases Cdc42 and Racl for adult hippocampal neurogenesis. J Neurosci 33: 1179-1189. CrossRef Medline

Wiltgen BJ, Silva AJ (2007) Memory for context becomes less specific with time. Learn Mem 14:313-317. CrossRef Medline

Yu SY, Wu DC, Liu L, Ge Y, Wang YT (2008) Role of AMPA receptor trafficking in NMDA receptor-dependent synaptic plasticity in the rat lateral amygdala. J Neurochem 106:889899. CrossRef Medline 